\title{
Marine Polysaccharides and their Conversion into Functional Materials
}

\author{
Mike Robitzer and Françoise Quignard*
}

\begin{abstract}
Natural polysaccharides are supports for sensors, absorbents and catalysts. They are also gelling agents in the aqueous phase, due to the high level of dispersion of hydrocolloids. This article focuses on an effective method to prepare dry materials which retain the dispersion of the polymer hydrogel, namely polysaccharide aerogels. The diverse surface functionalities like hydroxy, carboxy or amino groups of the polysaccharide aerogels are accessible to catalysts and reactants and can be easily modified to tune the functionality of the materials.
\end{abstract}

Keywords: Aerogels · Catalysis · Polysaccharides · Porous materials · Textural properties

\section{Introduction}

Hydrocolloid-forming polysaccharides are natural polyelectrolytes able to gelify water when added in tiny amounts. Hydrogels containing $1-2 \%$ polymer and $98-99 \%$ water can be shaped as self-standing spheres or films with good mechanical stability. This property is the basis of their natural function as water-storage agents for living organisms as well as their main industrial application, in which about 45,000 $\mathrm{t} \mathrm{y}^{-1}$ of seaweed-extracted polysaccharides are used as thickening agents for the food industry.

Natural polysaccharides, which have been known for many years as supports for enzymatic catalysts, have recently received increased attention as supports for metal catalysts. Indeed, polysaccharides fulfill most of the properties needed for adsorption or remediation ${ }^{[1-4]}$ applications. However, their use in catalysis suffers from diffusion limitations, due to the low surface area of the dried materials, xerogels or lyophilised solids, generally used. This article focuses on the potential benefits of

${ }^{*}$ Correspondence: Dr. F. Quignard Institut Charles Gerhardt Montpellier CNRS-ENSCM-UM2-UM1

ENSCM 8 rue de l'Ecole Normale

34296 Montpellier Cedex 5-France

Tel.: 33467163460

Fax: 33467163470

E-mail: quignard@enscm.fr

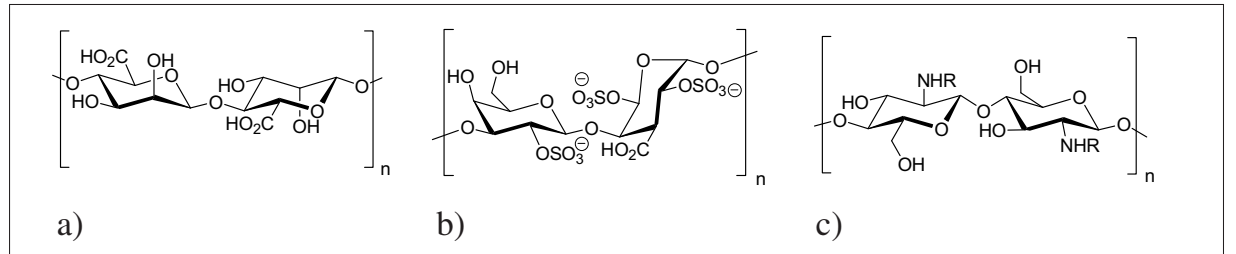

Fig. 1. a) alginate; b) carrageenan; c) chitosan.

an aerogel formulation of polysaccharides for selected applications.

\section{From Hydrocolloids to Porous Materials}

Natural polysaccharides available on industrial scale include polymers with carboxylic groups (alginates) or sulphonic groups (carrageenans) derived from seaweed, or with amino groups (chitosan), obtained by deacetylation of chitin from seafood shells (Fig. 1).

Alginates are block copolymers constituted of $(1-4)$ linked $\beta$-D-mannuronate (M) and $\alpha$-L-guluronate $(\mathrm{G})$ residues (Fig. 1a). Alginates are widely applied in drug release systems ${ }^{[5]}$ for the entrapment of biologically active materials. ${ }^{[6]}$ Carrageenans are a large family of sulphate-bearing polygalactoses (Fig. 1b) Carrageenans beads are often used as a matrix to entrap molecules of biological significance, such as food products, enzymes, and cells. ${ }^{[7,8]}$ Chitosan is a linear copolymer of linked $\beta$-(1,4)-glucosamine (Fig. 1c), traditionally obtained by deacetylation of chitin (poly- $\beta$ - $(1,4)$-acetylglucosamine) from seafood industry wastes (crab and shrimp shells and squid pens). Chitosan finds wide application in biomaterials, drug-delivery systems, ${ }^{[9,10]}$ food additives, water clarification, ${ }^{[11]}$ and as support for cells and enzymes. ${ }^{[12]}$
The gelling procedure starts from a solution of the polysaccharide in an appropriate solvent; water for $\mathrm{Na}$-alginate, acidic solution for chitosan. This viscous solution is added dropwise in the coagulating bath which may contain metal salts, ${ }^{[13,14]}$ or hydrochloric acid for sodium alginate, ${ }^{[15-18]}$ or a neutralization step with a concentrated alkaline solution (generally $\mathrm{NaOH}$ ) for chitosan. ${ }^{[19-21]}$ The principle of carrageenan beads formation is the thermo- and ionotropic gelation of $\kappa$-carrageenan hot droplets falling into a cold saline $(\mathrm{KCl})$ solution. The properties of the alginate gels are affected by the ratio and sequencing of uronate monomers (mannuronate or guluronate), ${ }^{[22]}$ the concentration of cations in the gelling bath and the time of ripening in the gelling solution. ${ }^{[23,24]}$ The degree of deacetylation and molecular weight of chitosan influence the physico-chemical properties (such as solubility and viscosity) and can determine the field of application of chitosan.

The preparation of polysaccharide aerogels involves several steps, which are exemplified in Fig. 2 by the preparation of a Ca-alginate aerogel. The first step is the formation of a hydrogel by reaction of a $\mathrm{Na}$-alginate solution with a $\mathrm{Ca}^{2+}$ solution. The microspheres are then dehydrated by immersion in a series of successive ethanol-water baths of increasing alcohol concentration $(10,30,50,70,90$ and $100 \%)$. Finally, the microspheres are dried under 




Fig. 2. Ca-alginate aerogel formation.

supercritical $\mathrm{CO}_{2}$ conditions (74 bars, 31.5 $\left.{ }^{\circ} \mathrm{C}\right)$. Hydrogel spheres are not stable to evaporative drying and shrink to xerogel particles with no porosity. In contrast, $\mathrm{CO}_{2}$ supercritical drying allows the apparent volume of the hydrogel spheres to be retained.

Ca-alginate materials were studied by small-angle X-ray scattering (SAXS) at different steps of conversion from gel to aerogel in order to determine the relation between the polymer organization at the nanoscale in the gels and the final dry aerogel. ${ }^{[25]}$ In all cases, i.e. before and after the different exchanges of solvents and after the formation of the aerogel, the SAXS patterns exhibit an asymptotic behavior at low $q$ values close to $I(q) \sim q^{-1}$, indicative of randomly-oriented rod-like scattering objects. This is evidence that in the experimental conditions chosen, the morphology of the aerogel depends on the morphology of pre-existing objects within the gel, i.e. that the structure of the aerogel provides a correct image of the structure of the parent gel.

Optical and SEM pictures of beads of several polysaccharide hydrogels ( $\mathrm{Co}$ alginate, chitosan from $\alpha$-chitin, and $\kappa$-carrageenan) and the corresponding aerogels are reported in Fig. 3.[26]

\section{Textural Properties of Polysaccharides Aerogels}

Shrinkage of aerogels is paralleled by their porosity, the values of which are reported in Table 1. Nitrogen adsorption-desorption isotherms provide useful information about several textural properties.[27,28] The adsorption at low relative pressure allows the surface area of the samples to be evaluated. Total porosity can be calculated from the volume/mass ratio of the material.

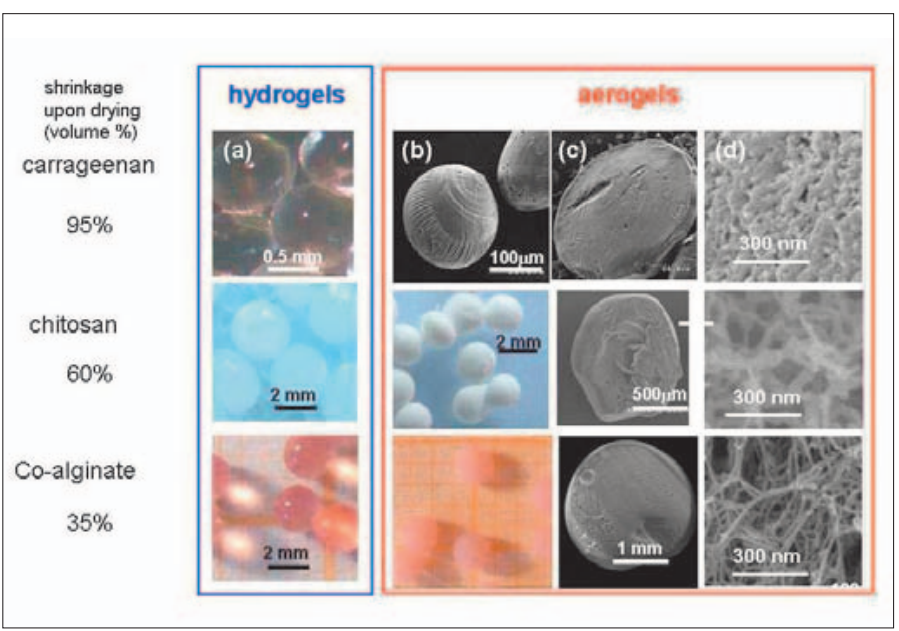

Fig. 3. Optical and SEM images of hydrogel (column a) and aerogel spheres (column b) and of cross-sections of aerogel spheres (column c, d) of carrageenan (line 1), chitosan (line 2) and Co-alginate (line 3).

Table 1. Typical textural data for polysaccharide aerogels

$\begin{array}{llll}\text { aerogel } & \begin{array}{l}\text { Surface area } \\ {\left[\mathrm{m}^{2} \mathrm{~g}^{-1}\right]}\end{array} & \begin{array}{l}\text { Porosity } \\ {\left[\mathrm{cm}^{3} \mathrm{~g}^{-1}\right]}\end{array} & \begin{array}{l}\text { Fibril diameter } \\ {[\mathrm{nm}]}\end{array} \\ \begin{array}{l}\text { Ca-alginate } \\ 570\end{array} & 39 & 4 \\ \text { Alginic acid } & 390 & 38 & 6 \\ \text { chitosan from } \alpha \text {-chitin } & 330 & 15 & 7 \\ \text { chitosan from } \beta \text {-chitin } & 150 & 19 & 16 \\ \kappa \text {-carrageenan } & 200 & 1 & 18\end{array}$

Total porosity of the alginate aerogels is about $38 \mathrm{~cm}^{3} \cdot \mathrm{g}^{-1}$, while chitosan has half this pore volume and the pore volume of carrageenan is 40 times smaller. Alginate and chitosan aerogels present an extremely open structure (Fig. 3, column d) and are essentially macroporous (pores with diameter larger than $50 \mathrm{~nm}$ ). All these aerogels are highly dispersed materials with surface areas in the range $150-600 \mathrm{~m}^{2} \cdot \mathrm{g}^{-1}$.

The aerogel from guluronate-rich alginates presents a more compact nanostructure than the mannuronate-rich sample, [29] in agreement with the better mechanical properties of guluronate-rich hydrogels.

\section{Accessibility of the Functional Groups}

The high surface area of the polysaccharide aerogels allows good accessibility to their functional groups. The assessment of this property is based on the spectroscopic $^{[30,31]}$ or chemical monitoring of the interaction of probe molecules with the functional groups. ${ }^{[32]}$

Transmission FT-IR spectroscopy has been used to monitor deuteration by $\mathrm{D}_{2} \mathrm{O}$ vapour at room temperature of wafers of aerogels of chitosan from $\beta$-chitin ${ }^{[33]}$ since deuteration can be used as a probe of the accessibility of the materials to small polar molecules. The accessibility of the primary amine functions of chitosan has been quantified in organic solvent by formation of a salicylaldimine Schiff base upon treatment with salicylaldehyde. In the aerogel formulation, up to $70 \%$ of the amine groups are accessible. ${ }^{[34]}$

In the case of polysaccharides, supercritical drying was originally used to prepare samples for electron microscopy. ${ }^{[35]}$ Recently new fields of applications emerged like drug delivery systems, ${ }^{[36]}$ adsorbents, catalysts or luminescent materials. ${ }^{[4]} \mathrm{A}$ few examples have been selected to illustrate some properties of polysaccharides aerogels.

\section{Catalysts Based on Chitosan or Alginate}

The high surface area and absence of diffusional limitations in the macroporous framework of polysaccharide aerogels, the high density and the accessibility of their functional groups (up to $5.6 \mathrm{mmol} \mathrm{g} \mathrm{m}^{-1}$ carboxylic groups for alginic acid, $5.8 \mathrm{mmol}$ $\mathrm{g}^{-1}$ amino groups for chitosan, $2.8 \mathrm{mmol}$ $\mathrm{g}^{-1}$ sulfate groups for $\kappa$-carrageenan) make polysaccharide aerogels promising materials for catalysis.

\subsection{Organocatalysis}

Chitosan aerogel microspheres have been successfully applied as a heteroge- 


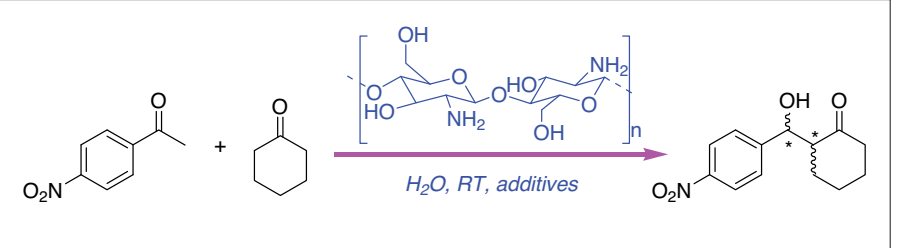

Scheme 1. Direct aldol reaction of cyclohexanone with $p$-nitrobenzaldehyde catalyzed by chitosan.

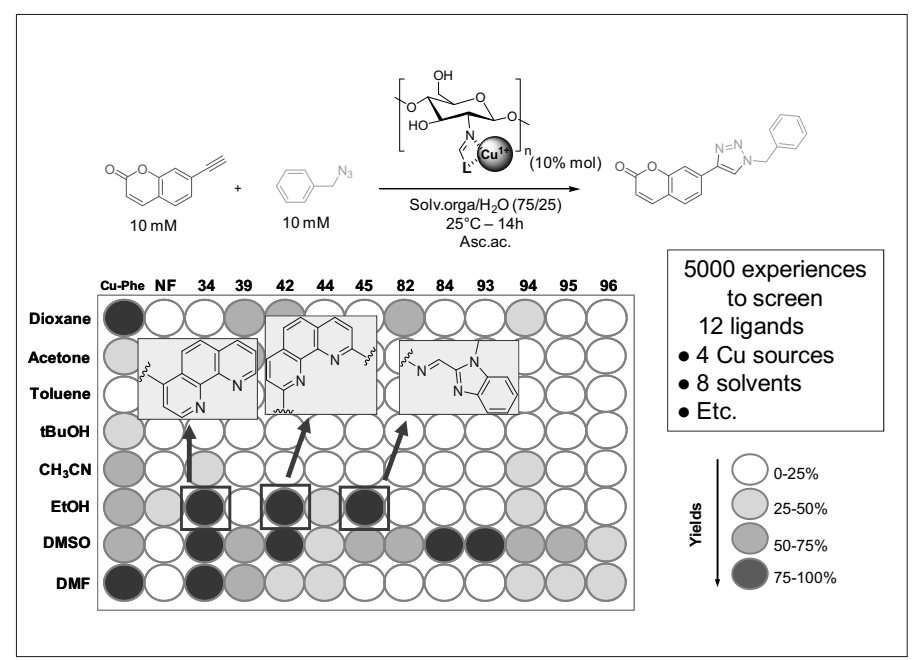

Fig. 4. Catalytic properties of $\mathrm{Cu}(1)$-chitosan complex in Huisgen's cycloaddition.

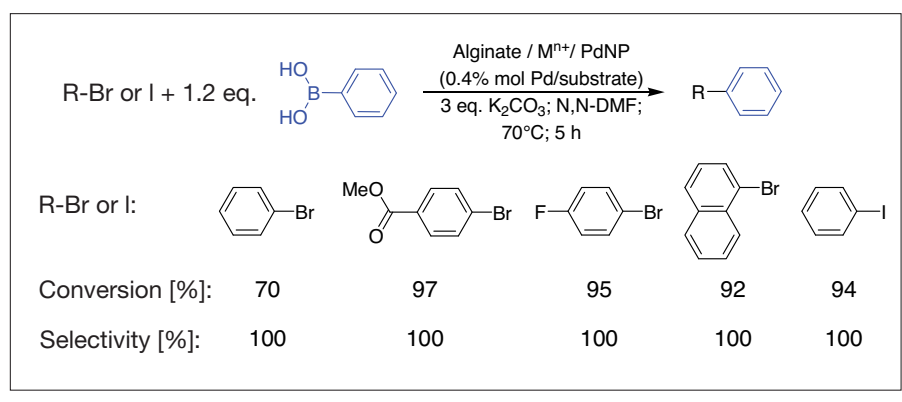

Fig. 5. Conversion of different substrates in the Suzuki reaction with 1.2 equivalents phenylboronic acid catalyzed by $\mathrm{Ca}, \mathrm{Pd} @$ Alginate $(2.5 \%)$, ( $0.4 \% \mathrm{~mol} \mathrm{Pd}$ vs. substrate, 3 equivalents of $\mathrm{K}_{2} \mathrm{CO}_{3}, \mathrm{~N}, \mathrm{~N}-\mathrm{DMF}, 70^{\circ} \mathrm{C}, 5 \mathrm{~h}$ ).



Fig. 6. Eu ${ }^{3+}-$ Alg Beads before UV radiation (upper row) and after UV $(395 \mathrm{~nm})$ radiation (lower row). Hydrogel $\left(A, A^{\prime}\right)$, aerogel $\left(B, B^{\prime}\right)$, alcogel (C,C'), xerogel (D,D'). neous organocatalyst ${ }^{[37]}$ in the first direct asymmetric aldol reaction that can be performed in the presence of water (Scheme 1) with high yields and good stereoselectivity (up to $93 \% e e$ ), and good recyclability (up to four runs).

\subsection{Metal-mediated Catalysis}

The most straightforward route to functionalize primary amine containing materials is the formation of an imine via a Schiff base formation between the nitrogen and an aldehyde moiety. ${ }^{[38,39]}$ Several ligands able to coordinate copper (I) ion have been anchored to the polymer scaffold with a rate up to $100 \%$. These compounds have been evaluated as catalyst in the [3+2]-cycloaddition reaction between azides and alkynes in the so-called Huisgen 'click' reaction. ${ }^{40]}$ The catalysts were shaped in control size beads which allowed high-throughput experiments in order to find the more efficient solvent, catalyst, base, etc. (Fig. 4). Finally, the best system was chitosan functionalized with a bidentate phenanthroline ligand under mild conditions $(0.1 \mathrm{~mol} \%$, $\mathrm{EtOH}, 4 \mathrm{~h}, 80^{\circ} \mathrm{C}$, in air, no additive, yield up to $98 \%$ ). This heterogeneous catalyst can be easily removed from the batch (with spatula or tweezers) and easily recycled (4th run: yield up to $93 \%$ ).

Finally, polysaccharides aerogels are good supports for the dispersion of metal nanoparticles. For instance, when reacted with $\mathrm{Na}_{2} \mathrm{PdCl}_{4}$, the $\mathrm{Ca}$ ions of the alginate matrix are exchanged by $\mathrm{Pd}(\mathrm{II})$ cations. During the further steps of preparation of the aerogel, Pd cations spontaneously reduce to metallic species, and metal nanoparticles are obtained (PdNP), homogeneously and highly dispersed in the biopolymer matrix.[41] The latter material showed high activity for Suzuki carboncarbon coupling reactions (Fig. 5) and the stability of the catalyst allowed several reuses with only a slight loss of activity.

\section{Luminescent Materials based on Ln $^{3+}$-Alginate or Chitosan}

Alginates form gels with lanthanide ions. ${ }^{[42]}$ The luminescent properties of $\mathrm{Eu}^{3+}$-alginate gels were investigated at 300 $\mathrm{K}$ for the different states from hydrogel to aerogel. ${ }^{43]}$ Under UV radiation, all the four states behave as light emitters at room temperature (Fig. 6). The $\mathrm{Eu}^{3+}$-alginate aerogel and alcogel exhibit the highest ${ }^{5} \mathrm{D}_{0}$ quantum efficiencies (9.9 and 8.2\%, respectively), while the hydrogel and xerogel have lower $Q$ values (5.2 and 5.6\%, respectively). The difference in the non-radiative transition probability may be rationalized on the basis of the different number of $\mathrm{OH}$ oscillators present in the $\mathrm{Eu}^{3+}$-first coordination shell $\left(\mathrm{n}_{\mathrm{OH}}=3.7 \pm 0.1\right.$ for aerogel and alcogel and $4.8 \pm 0.1$ for hydrogel and xerogel).
The presence of $\mathrm{OH}$ oscillators as well as $\mathrm{C}-\mathrm{H}$ oscillators close to the lanthanides are known to decrease the quantum efficiency by non-radiative desexcitation.

Under UV radiation, the $\mathrm{Eu}^{3+}-, \mathrm{Tb}^{3+}$, and $\mathrm{Tb}^{3+} / \mathrm{Eu}^{3+}$-based hybrids are roomtemperature emitters in the visible spectral range (Fig. 7), whereas for the remaining alginates, no intra-4f photoluminescence was detected.

The excitation spectrum of the $\mathrm{Tb}^{3+} /$ $\mathrm{Eu}^{3+}$-alginate hybrid (Eu/Tb: 0.90/0.10) is strongly modified when the excitation wavelength is modified. In fact this material is a multi-wavelength emitter, in which the emission color can be tuned across the chromaticity diagram by selecting the excitation wavelength (Fig. 8).

The excitation spectra of $\mathrm{Eu}^{3+}$ and $\mathrm{Tb}^{3+}$ doped chitosan hydrogel in water ${ }^{[44]}$ showed that chitosan is less effective as a support than alginate.

\section{Conclusions}

The attractiveness of the applications of polysaccharides as materials stems both from their availability from renewable resources and their intrinsic properties. The variety of polysaccharides with different functional groups renders them especially interesting as polymers with the surface reactivity needed for specific catalysis 


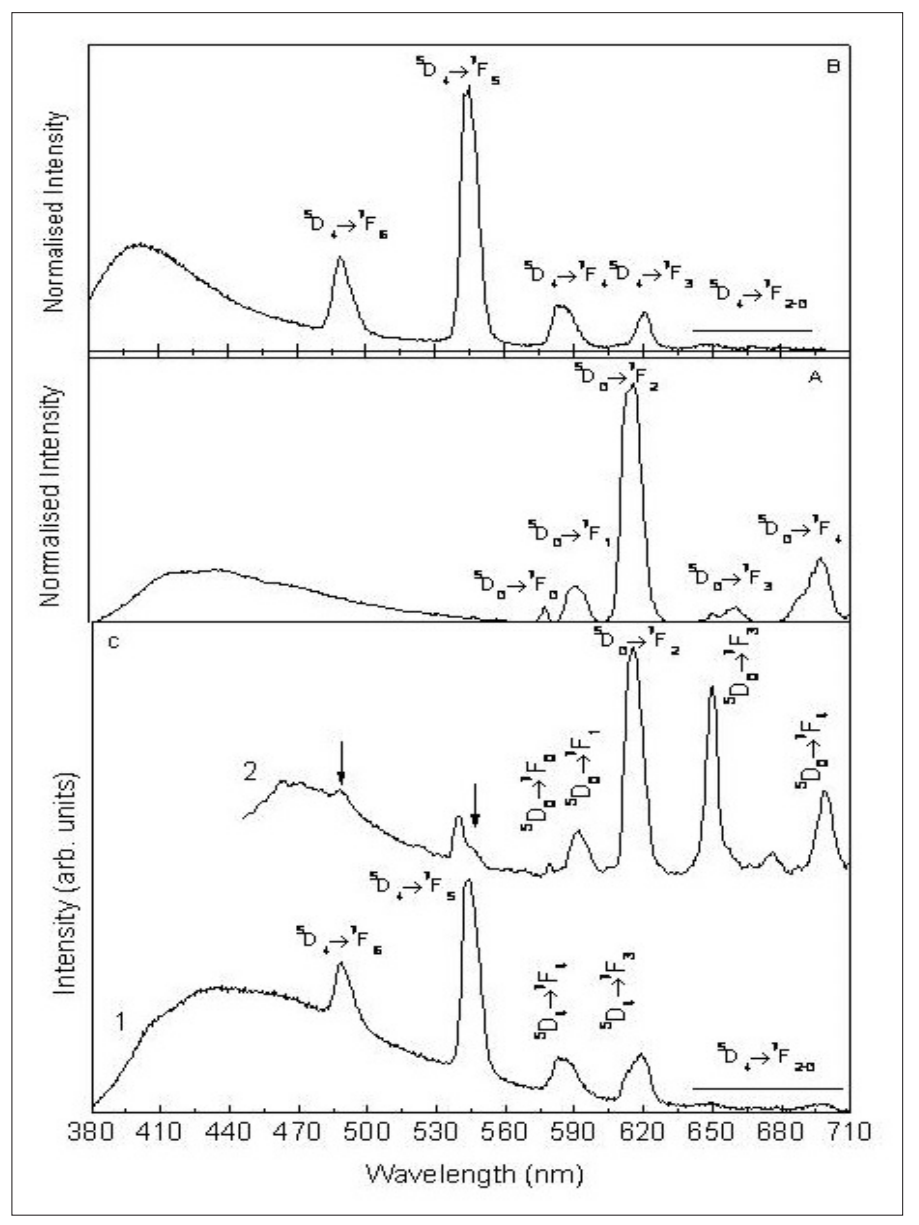

Fig. 7. Room

temperature emission spectra of : A) $\mathrm{Eu}^{3+}$-alg excited at $330 \mathrm{~nm}$; B) $\mathrm{Tb}^{3+}$-alg excited at $305 \mathrm{~nm}$; C) $\mathrm{Tb}^{3+} /$ $\mathrm{Eu}^{3+}$-alg with $[\mathrm{Tb} / \mathrm{Eu}]=$ 0.90:0.10 excited at (1) $368 \mathrm{~nm}$, and (2) $395 \mathrm{~nm}$ $($ alg $=$ alginate $)$.

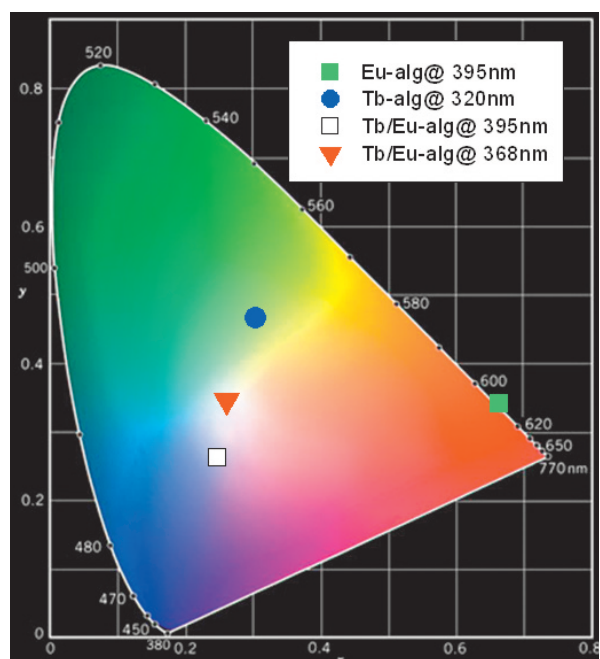

Fig. 8. CIE (1931) (x, y) chromaticity diagram showing the emission color coordinates of the $\mathrm{Eu}^{3+}-, \mathrm{Tb}^{3+}$ - and $\mathrm{Tb}^{3+} / \mathrm{Eu}^{3+}$-alginate hybrids under different excitation wavelengths (from ref. [43]). processes as well as for adsorption, separation and remediation processes. The intrinsic chirality of their glucidic backbone coupled to their easy formation in different shapes and sizes are among their most important assets. It seems thus obvious that the origin of the natural resource, the state in which the gel is used, the functionalization, etc. are important parameters that influence chemical and optical properties of the final materials.

Received: September 27, 2010

[1] E. Guibal, Prog. Polym. Sci. 2005, 30, 71.

[2] D. J. Macquarrie, J. J. E. Hardy, Ind. Eng. Chem. Res. 2005, 44, 8499.

[3] E. Guibal, Sep. Purif. Technol. 2004, 38, 43.

[4] F. Quignard, E. Guibal, F. Di Renzo, Topics Curr. Chem. 2010, in press.

[5] H. H. Tønnesen, J. Karlsen, Drug Dev. Ind. Pharm. 2002, 28, 621.

[6] N. O. Dhoot, M. A. Wheatley, J. Pharm. Sci. 2003, 92, 679 and references therein.

[7] P. K. Walsh, F. V. Isdell, S. M. Noone, M. G. O'Donovan, D. M. Malone, Enzyme Microb. Tech. 1996, 18, 366.

[8] O. Sipahigil, B. Dortunc, Int. J. Pharm. 2001, 228,119

[9] P. Gerentesa, L. Vachoud, J. Dourya, A. Domard, Biomaterials 2002, 23, 1295.

[10] V. R. Sinha, A. K. Singla, S. Wadhawan, R. Kaushik, R. Kumria, K. Bansal, S. Dhawan, Int. J. Pharm. 2004, 274, 1.

[11] J. G. Winterowd, P. A. Sandford, 'Food Polysaccharides and their Applications', Ed. A. M. Stephen, Marcel Dekker: New York, 1995, p 441.
[12] J. N. Barbotin, J. E. Nava Saucedo, 'Polysaccharides', Ed. S. Dumitriu, Marcel Dekker: New York, 1998, 749.

[13] G. Fundueanu, C. Nastruzzi, A. Carpov, J. Desbrieres, M. Rinaudo, Biomaterials 1999, 20 , 1427.

[14] K. Potter, E. W. McFarland, Solid State Nucl. Magn. Reson. 1996, 6, 323.

[15] Y. Konishi, J. I. Shimaoka, S. Asai, React. Funct. Polym. 1998, 36, 197.

[16] K. I. Draget, G. Skjak-Braek, O. Smidsrød, Carbohyd. Polym. 1994, 25, 31.

[17] K. S. Khairou, W. M. Al-Gethami, R. M. Hassan, J. Membr. Sci. 2002, 209, 445.

[18] K. S. Khairou, W. M. Al-Gethami, R. M. Hassan, Bull. Pol. Acad. Sci., Chem. 2002, 50, 299.

[19] E. B. Denkbas, E. Kiliçay, C. Birliksevenand, E. Oztürk, React. Funct. Polym. 2002, 50, 225.

[20] E. B. Denkbas, M. Odabasi, J. Appl. Polym. Sci. 2000, 76, 1637.

[21] G. L. Rorrer, T.-Y. Hsien, J.D. Way, Ind. Eng. Chem. Res. 1993, 32, 2170.

[22] O. Smidsrød, Faraday Discuss. Chem. Soc. 1974, 57, 263

[23] C. Ouverx, N. Velings, M. M. Mestdagh, M. A. V. Axelos, Polym. Gels Networks 1998, 6, 393

[24] N. Velings, M. M. Mestdagh, Polymer Gels Networks 1995, 3, 11.

[25] M. Robitzer, L. David, C. Rochas, F. Di Renzo, F. Quignard, Langmuir 2008, 24, 12547.

[26] F. Quignard, R. Valentin, F. Di Renzo, New J. Chem. 2008, 32, 1300 .

[27] S. J. Gregg, K. S. W. Sing, 'Adsorption, Surface Area and Porosity', Academic Press, London, 1982.

[28] F. Rouquerol, J. Rouquerol, K. Sing, 'Adsorption by powders and porous solids', Academic Press, San Diego, 1999

[29] R. Valentin, K. Molvinger, F. Quignard, F. Di Renzo, Macromol. Symp. 2005, 222, 93 .
[30] R. Valentin, R. Horga, B. Bonelli, E. Garrone, F. Di Renzo, F. Quignard, Macromol. Symp. 2005, 230,71 .

[31] R. Valentin, R. Horga, B. Bonelli, E. Garrone, F. Di Renzo, F. Quignard, Biomacromolecules 2006, 7, 877 .

[32] R. Rodriguez Escudero, M. Robitzer, F. Di Renzo, F. Quignard, Carbohydrate Polymers 2009, 75, 52 .

[33] R. Valentin, B. Bonelli, E. Garrone, F. Di Renzo, F. Quignard, Biomacromolecules 2007, 8, 3646.

[34] R. Valentin, K. Molvinger, F. Quignard, D. Brunel, New J. Chem. 2002, 27, 1690.

[35] C. Ouverx, N. Velings, M. M. Mestdagh, M. A. V. Axelos, Polym. Gels Networks 1998, 6, 393.

[36] T. Mehling, I. Smirnova, U. Guenther, R. H. H. Neubert, J. Non Cryst. Sol. 2009, 355, 2472.

[37] A. Ricci, L. Bernardi, C. Gioia, S. Vierucci, M. Robitzer, F. Quignard, Chem. Commun. 2010, 46,6288 .

[38] J. J. E. Hardy, S. Hubert, D. J. Macquarrie, A. J. Wilson, Green Chem. 2004, 6, 53.

[39] K. Justi, M. C. M. Laranjeira, A. Neves, A. S. Mangrich, V. F. Favere, Polymer 2004, 45, 6285.

[40] M. Chtchigrovsky, A. Primo, P. Gonzalez, K. Molvinger, M. Robitzer, F. Quignard, F. Taran, Angew. Chem. Int. Ed. 2009, 48, 5916.

[41] A. Primo, M. Liebel, F. Quignard, Chem. Mater. 2009, 21, 621.

[42] C. M. DeRamos, A. E. Irwin, J. L. Nauss, B. E. Stout, Inorg. Chim. Acta 1997, 256, 69.

[43] F. Liu, L. D. Carlos, R. A. Sá Ferreira, J. Rocha, M. C. Gaudino, M. Robitzer, F. Quignard, Biomacromolecules 2008, 9, 1945.

[44] F. Liu, L. D. Carlos, R. A. Sa Ferreira, J. Rocha, M. Ferro, A. Tourrette, F. Quignard, M. Robitzer, J. Phys. Chem. B 2010, 114, 77. 